\title{
"Flashes" of Chlorophyll-a Concentration Derived from in Situ and Remote Sensing Data at the Polar Front in the Barents Sea
}

\author{
Vladimir Kushnir ${ }^{1}$, Vladimir Pavlov ${ }^{*}, 2$, Alexey Morozov ${ }^{1}$ and Olga Pavlova ${ }^{2}$ \\ ${ }^{I}$ Marine Hydrophysical Institute, National Academy of Science of Ukraine, Sevastopol, Ukraine \\ ${ }^{2}$ Norwegian Polar Institute, Tromsø N-9296, Norway
}

\begin{abstract}
The Polar Front Zone (PFZ) in the Barents Sea is an area where warm, salty water of the North Atlantic (AtW) interacts with cold, less dense, Arctic water (ArW) and the fresher water produced by melting ice (MW). In the spring a large-scale transformation of the structure of the PFZ is accompanied by the development of mesoscale eddies with characteristic sizes of 25 to $40 \mathrm{~km}$. The vertical velocity in the centre of such cyclonic eddies can be up to $20 \mathrm{~m} / \mathrm{day}$, transporting deep water with high nutrient concentration up to the surface. Photosynthesis at the surface leads to intense phytoplankton development, which is registered by the color scanners of SeaWiFS and MODIS as a sharp increase, or "flash," in chlorophyll-a concentration. A statistical analysis of such flashes for the last 11 years has shown that the most probable time for their occurrence is the last week of May. Maxima of the chlornnhyll-a concentration have a Rayleigh distribution with a mean of $3.82 \mathrm{mg} / \mathrm{m}^{3}$ and a standard deviation of $1.98 \mathrm{mg} / \mathrm{m}^{3}$. The characteristic sizes of the areas where a flash occurs correspond to the size of mesoscale eddies determined from estimations of the internal Rossby deformation radius. The positions of these eddies, observed by the R/V "Lance" survey coincide with the zones of high chlorophyll-a concentration seen in the data from the optical scanner of SeaWiFS.
\end{abstract}

Keywords: Barents Sea, Polar Front Zone (PFZ), chlorophyll-a concentration, mesoscale eddies.

\section{INTRODUCTION}

The Barents Sea is a marginal sea of the Arctic basin and it is one of the regions of the World Ocean with highest biological productivity. Human activity in this area is mainly concerned with the rich fisheries here, which are dependent on the biological productivity and its variability.

The main oceanographic feature of the Barents Sea is the interaction between the warm and salty waters from the Northern Atlantic (AtW), the less saline and colder Arctic water (ArW), and the locally produced water masses, such as melt water (MW). This interaction occurs mainly in the Polar Front Zone (PFZ) which occupies the central part of the Barents Sea, between Svalbard and the southern coast of Novaya Zemlya, during the winter. In the summer the PFZ in the upper layer is displaced northwards to $78-80^{\circ} \mathrm{N}$. The PFZ is a narrow zone with sharp horizontal gradients in temperature and/or salinity separating two water masses. In most winters ice covers the PFZ and extends southward into the AtW. When the ice melts during the spring and summer the ice-edge retreats north over the PFZ. This has a significant effect on the productivity of the region.

The interaction of water masses with different thermohaline characteristics in the PFZ influences the vertical and horizontal mixing in the region, and hence the transformation processes along the path of the AtW. Fronts, including the PFZ, are sites of high biological productivity and concentrations of food organisms, and are important

*Address correspondence to this author at the Norwegian Polar Institute, Polar Environmental Centre, Tromsø N-9296, Norway; Tel.: +47 77750516; Fax:+47 77750501; E-mail: pavlov@npolar.no feeding areas for many commercial fish species. Fronts can also act as barriers to many marine organisms.

The above factors explain why there is such interest in studying the PFZ in the Barents Sea. Many scientific studies have been carried out, resulting in a large number of published works, for example the papers [1-11].

In recent decades, remote sensing methods have been used to study the structure of the PFZ. The main sources of data are the measurements made by the color scanners of the SeaWiFS and MODIS systems. These data differ from traditional of ship based measurements by having higher resolution (1-10 km) and covering a larger scale (about 2000 $\mathrm{km}$ for individual images). Remote sensing methods measure the brightness of the water surface in the visible, infra-red and thermal wavelengths (from $412 \mathrm{~nm}$ till 10-13 $\mu \mathrm{m}$ ). These measurements are used to infer the distributions of chlorophyll-a, surface temperature and other parameters [1218 .

Despite intensive study of the PFZ using surface based and satellite measurements, our understanding of the physics the front and its influence on the biological productivity is poor. The relative importance of physical processes, such as eddies, turbulent mixing and transport, convection, convergence, upwelling and wind forcing is still unclear. It is not known what effect the disappearance of the ice could have on productivity in the vicinity of the PFZ.

Study of the PFZ is vital to improve our understanding the physical and biological processes in the Barents Sea. The value of this information for commercial fisheries was the reason that the project "Norwegian Component of the Ecosystem Studies of Subarctic and Arctic Regions (NESSAR)" was established. NESSAR is funded by the 


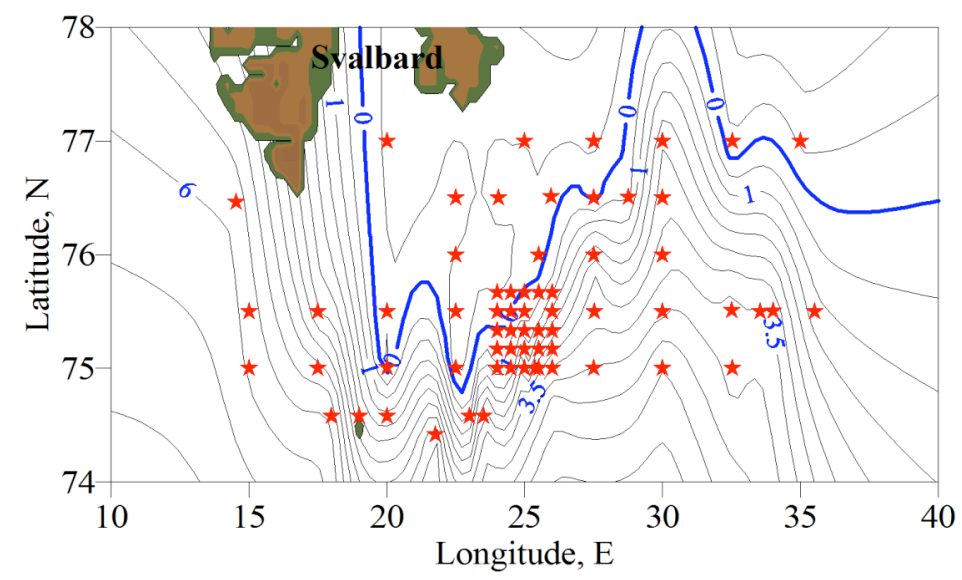

Fig. (1). Positions of the oceanographic stations (asterisk) plotted on a background of the surface temperature.

Research Council of Norway (RCN), the International Polar Year initiative. Some results from NESSAR are presented below. These results are based on ship based measurements of oceanographic parameters (temperature, salinity, density), carried out by an expedition from the Norwegian Polar Institute (NP), Tromsø, Norway on R/V "Lance" in MayJune 2007, and on the data from the optical scanners of SeaWiFS and MODIS which are freely distributed by NASA (http://oceancolor.gsfc.NASA.gov). This paper concentrates on the problem of the spatial structure of the chlorophyll-a concentration, where mesoscale heterogeneities with abnormally high values are observed on short timescales. These maxima show up as "flashes" of the chlorophyll-a concentration against the background values in the PFZ in spring and summer. Here we examine the basic statistical characteristics of these mesoscale anomalies in the chlorophyll-a concentration and discuss possible mechanisms for their formation. A better understanding of this prominent aspect of the structure of the PFZ may also enable us to make better forecasts of this phenomenon.

\section{MATERIALS AND METHODS}

The positions of the oceanographic stations from the NP expedition on R/V "Lance" carried out from May 30 till June 212007 are shown in Fig. (1). Measurements of the profiles of temperature, salinity and density (CTD data) were performed with a SBE 9 "Sea-Bird". The data were averaged to one meter intervals. The distribution of the surface temperature derived from the CTD data is shown in Fig. (1). An area with high horizontal gradients can be clearly seen. The zero degree isotherm divides water with temperatures above zero (AtW) from water with temperatures below zero (ArW) and corresponds to the position of the PFZ.

Potential density data, $\sigma_{t}$, were used to calculate buoyancy frequency,

$$
\mathrm{N}=\left(\frac{\mathrm{g}}{\left(1000+\sigma_{\mathrm{t}}\right)} \frac{\Delta \sigma_{\mathrm{t}}}{\Delta \mathrm{z}}\right)^{0.5}
$$

and the baroclinic deformation radius (internal Rossby radius),

$$
\mathrm{R}_{\mathrm{b}}=(<\mathrm{N}>\cdot \mathrm{H}) / \mathrm{f},
$$

where $\mathrm{g}=9.81 \mathrm{~m} / \mathrm{s}^{2}$ is the acceleration of gravity, $\Delta \mathrm{z}$ is the depth interval used to calculate the vertical gradient of the potential density (here $\Delta \mathrm{z}=5 \mathrm{~m}$ ), $\mathrm{H}$ is the sea depth, and $\mathrm{f}$ is the Coriolis parameter $\left(\mathrm{f}=1.4 \times 10^{-4} \mathrm{rad} / \mathrm{s}\right)$.

Remote measurements of the chlorophyll-a concentration and sea surface temperatures (SST) were carried out by the optical scanners of SeaWiFS and MODIS. From SeaWiFS we used composite images averaged over 8 days for the period September 1997 to September 2008. From MODIS the composite images were averaged over one month and data for the period 2003 to 2008 were used. Both data sets have a spatial resolution of $0.1^{\circ}$ or $11 \mathrm{~km}$.

Estimations of the reliability of the chlorophyll-a concentration from the SeaWiFS data are given in $[19,20]$. The southeastern Barents Sea shows a clear bias and high root mean square (RMS) log error. These five points are all coastal, suggesting contamination by drifting, subpixel-scale sea ice undetected in the processing algorithms. In the eastern Barents Sea remote sensing chlorophyll-a data are consistent with other observations. The chlorophyll-a distribution patterns observed in the satellite images are consistent with field observations. The remote sensing data provide additional information because of their higher spatial resolution $[12,17,21]$.

Comparison of the direct measurements of SST and satellite SST data for the period 1987 to 1992 (using over 22,000 values) has shown that there is a small divergence, of $0.3^{\circ} \mathrm{C}$, between these data, and a significant noise component (from $1^{\circ} \mathrm{C}$ in southern areas of the sea up to $2.5^{\circ} \mathrm{C}$ at 75 $76^{\circ} \mathrm{N}$ ). This increase is connected with floating ice. The constant divergence was corrected by introducing the appropriate amendment, and noise component is reduced to $\sigma_{\mathrm{T}} \leq(0.2-0.3)^{\circ} \mathrm{C}$ by averaging during the data processing. This was made possible by the frequent orbit of the satellites over the Barents Sea, giving approximately 20 measurements/day [22].

To determinate the temporal variability of the mesoscale anomalies of the chlorophyll-a concentration, the PFZ area was divided into the following segments: $15-20^{\circ} \mathrm{E}, 74-76^{\circ} \mathrm{N}$; $20-25^{\circ} \mathrm{E}, 73-74.5^{\circ} \mathrm{N} ; 25-30^{\circ} \mathrm{E}, 74-75^{\circ} \mathrm{N} ; 30-35^{\circ} \mathrm{E}, 76-77^{\circ} \mathrm{N}$; $35-40^{\circ} \mathrm{E}, 74-76^{\circ} \mathrm{N} ; 40-45^{\circ} \mathrm{E}, 74-76^{\circ} \mathrm{N} ; 45-50^{\circ} \mathrm{E}, 74-76^{\circ} \mathrm{N}$. 
Composite images for 8 day periods were averaged over each of these segments, and the temporal variability of the chlorophyll-a concentration was determined for the period from 1998 to 2008. The features of the optical measurements in PFZ (namely, rich and practically continuous overcast) were taken into account at the definition of sizes of the specified segments. The influence of these factors was somewhat compensated by a lot of daily images (above 20/day). Analysis showed that reducing the sizes of the segments resulted in a large number of missing data.

Statistical analysis of the mesoscale anomalies of the chlorophyll-a concentration was carried out by calculating histograms of the probability distributions of the timing of the chlorophyll-a flashes and values of their maxima. Analytical ratio for density of the probabilities distribution of the specified parameters is executed on the basis of the calculation of the first-fourth orders moments.

\section{RESULTS AND DISCUSSION}

The analysis of the chlorophyll-a concentration measured by the optical SeaWiFS scanner (Fig. 2) shows that there are sharp differences (flashes) of the chlorophyll-a concentration in the PFZ. This figure shows the temporal variability of the chlorophyll-a concentration averaged over the segment of the PFZ with coordinates $15-20^{\circ} \mathrm{E}, 74-76^{\circ} \mathrm{N}$ for the period of 1998-2008. Similar results are observed for the other six PFZ segments investigated.

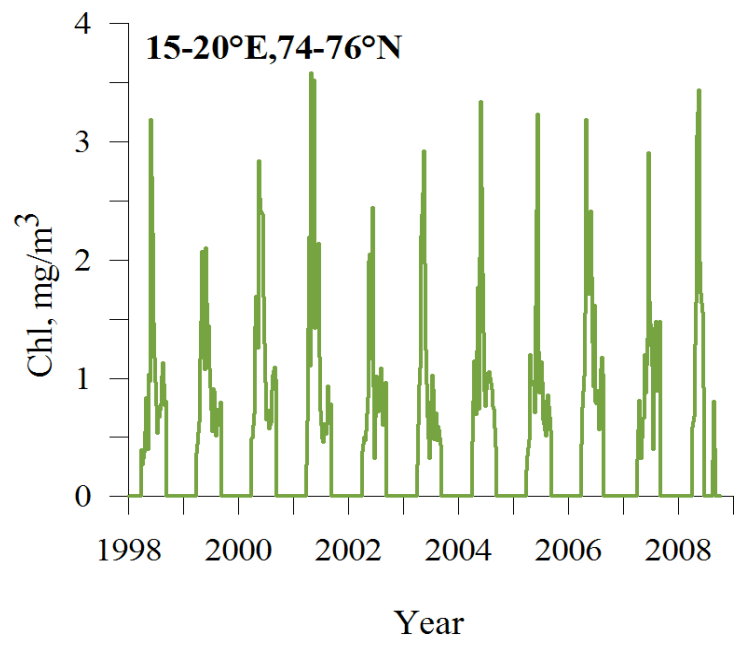

Fig. (2). Time variability of the chlorophyll-a concentration in the western PFZ.

These data were used to calculate the probability distributions of the timing of the flash maximum and its size. The corresponding histograms are shown in Fig. (3) and Fig. (4). The distribution of flash timing, shown in Fig. (3), corresponds to a normal distribution,

$\mathrm{W}(\mathrm{w})=\frac{1}{\sqrt{2 \pi} \sigma_{\mathrm{w}}} \exp \left[-\frac{(\mathrm{w}-<\mathrm{w}>)^{2}}{2{\sigma_{\mathrm{w}}}^{2}}\right]$

Calculating the first and second moments of this distribution gives an average value of $\left.<_{\mathrm{w}}\right\rangle=18$ (corresponding to May 20-28), with a standard deviation of $\sigma_{\mathrm{w}}=1.7$. Based on these data the most probable period for a chlorophyll-a flash formation is 20-28 May.

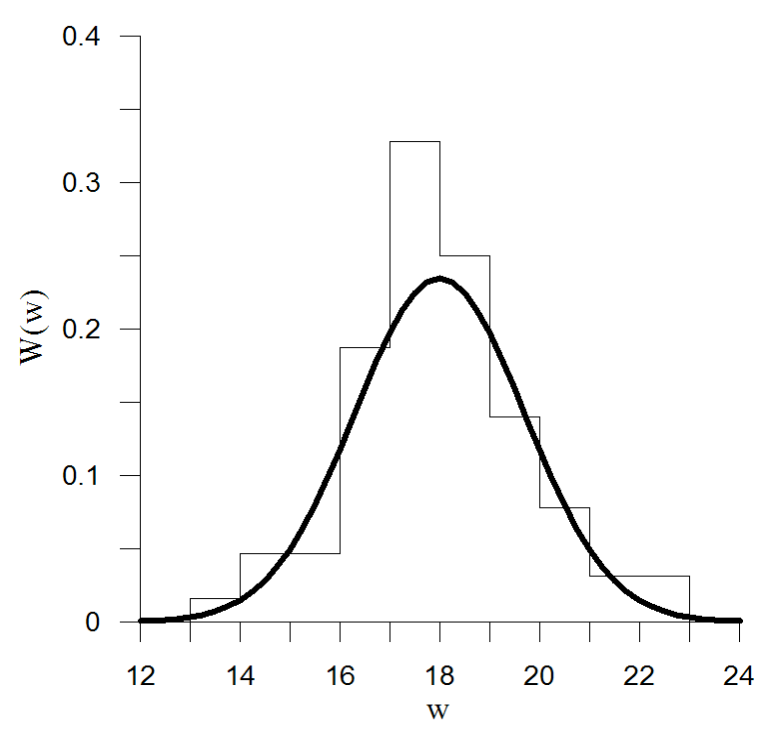

Fig. (3). Histogram of the timing of chlorophyll-a flashes and its approximation by a normal distribution. The number on the $\mathrm{x}$-axis corresponds to number of the eight-day time composite image of the SeaWiFS scanner.

The histogram in Fig. (4) clearly deviates from a normal distribution. The first four moments were calculated for this distribution and used to determine the average value $<\mathrm{Ch} 1_{\max }>$, standard deviation $\sigma_{\mathrm{C}}$ (see Fig. 4), coefficient of asymmetry $\left(\gamma_{\mathrm{a}}=0.66\right)$ and an excess $\left(\gamma_{\mathrm{e}}=-0.16\right)$.

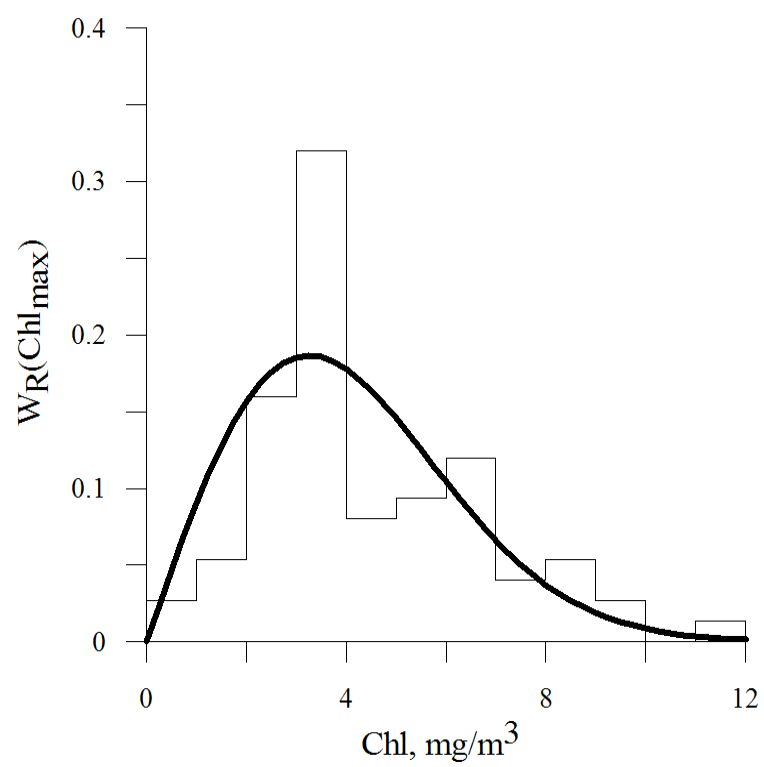

Fig. (4). Histogram of the maximum values of chlorophyll-a concentration and its approximation by Rayleigh distribution with the parameters $<\mathrm{Chl}_{\max }>=3.82 \mathrm{mg} / \mathrm{m}^{3} \quad \sigma_{\mathrm{c}}=1.98 \mathrm{mg} / \mathrm{m}^{3}, \sigma_{\mathrm{R}}=$ $3.256 \mathrm{mg} / \mathrm{m}^{3}$.

The parameters $\gamma_{a}, \gamma_{c}$ are close to similar parameters for a Rayleigh probability distribution and this distribution was therefore used to approximate the histogram in Fig. (4). The parameter $\sigma_{R}$ of the Rayleigh distribution of,

$\mathrm{W}(\mathrm{C})=\frac{\mathrm{C}}{{\sigma_{\mathrm{R}}}^{2}} \exp \left(-\frac{\mathrm{C}^{2}}{2{\sigma_{\mathrm{R}}}^{2}}\right), \mathrm{C} \geq 0$

was determined to be, 

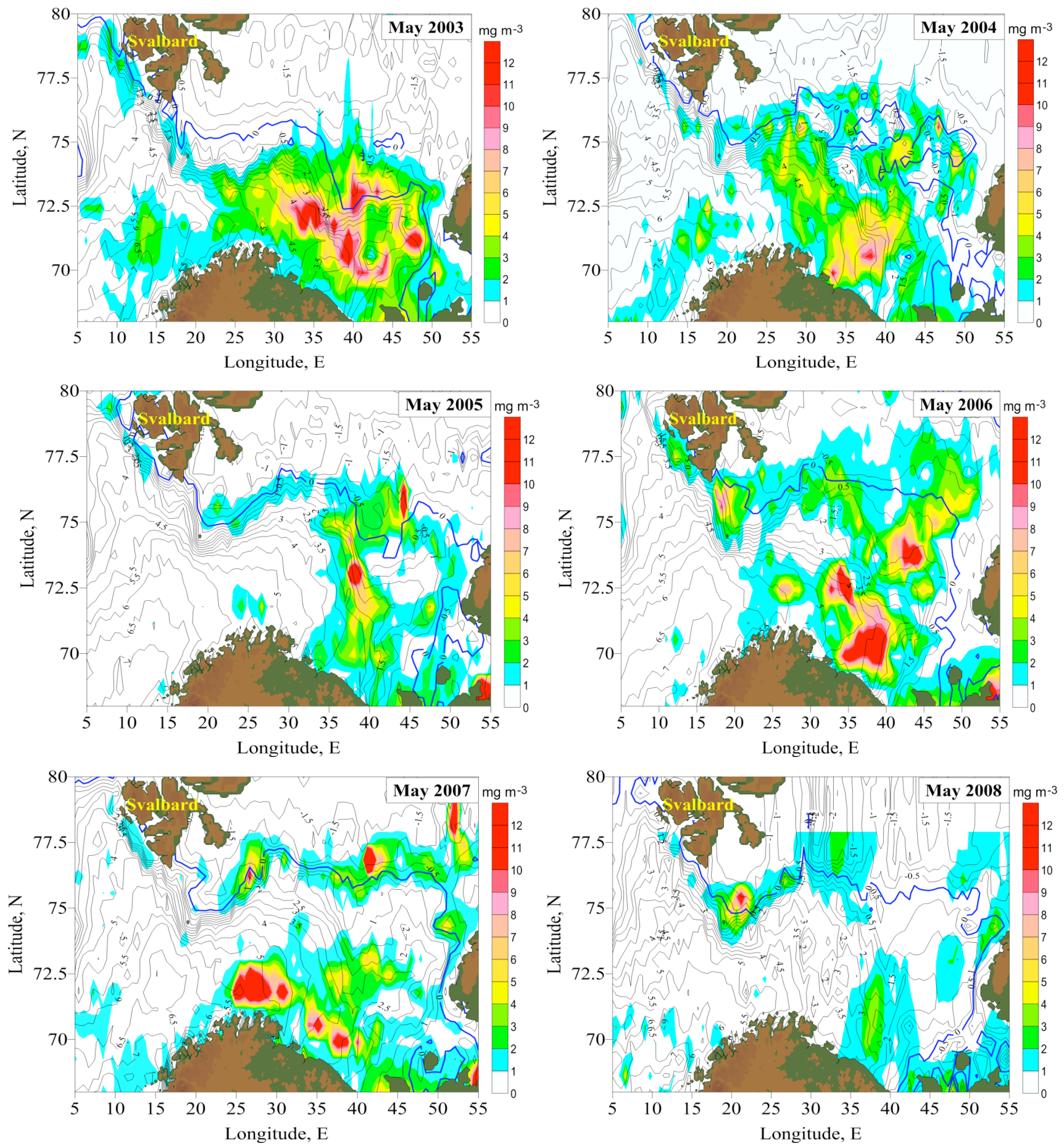

Fig. (5). Spatial distributions of the chlorophyll-a concentration for 2003 - 2008 plotted on a background of SST isolines (MODIS, $11 \mu \mathrm{m}$ thermal channel).

$\sigma_{\mathrm{R}}=\sqrt{\frac{2}{4-\pi}} \sigma_{\mathrm{C}}$.

This Rayleigh distribution can be used to forecast the maximum values of the chlorophyll-a concentration.

Spatial distributions of the chlorophyll-a concentration were calculated using composite images from the optical scanner of MODIS for 2003-2008 for May, since the highest probability for a chlorophyll-a flash occurs in May (Fig. 3). These distributions are shown in Fig. (5) and have the following features:

1. Flashes of the chlorophyll-a concentration are close to or in the PFZ, defined as the zone of maximum horizontal temperature gradients.

2. The characteristic sizes of the areas of high chlorophyll-a concentration are $25-40 \mathrm{~km}$, which coincides 

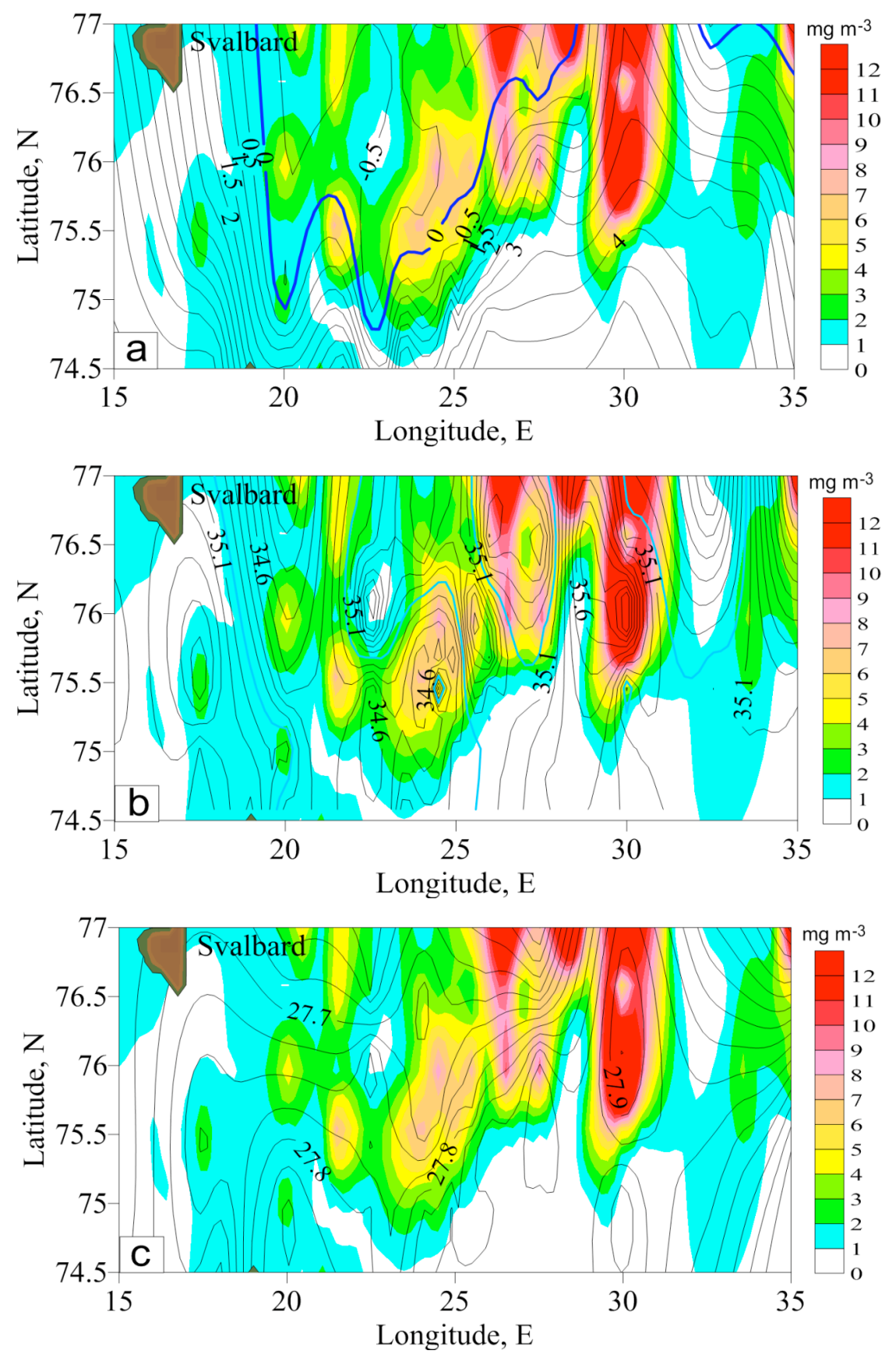

Fig. (6). Spatial distributions of the chlorophyll-a concentration $\left(\mathrm{mg} / \mathrm{m}^{3}\right.$, SeaWiFS, color areas) and SST $\left({ }^{\circ} \mathrm{C}\right)$-a, salinity (psu)-b, potential density $\left(\sigma_{t}\right)$-c, derived from data collected during the oceanographic survey carried out by R/V "Lance" in May-June 2007.

with the scales of mesoscale eddies that are observed in the PFZ [10, 23, 24].

Under the oceanographic survey carried out by $\mathrm{R} / \mathrm{V}$ "Lance" (Fig. 1) a zone of high chlorophyll-a concentration was observed to coincide with a mesoscale eddy in the PFZ. Spatial distributions of the chlorophyll-a concentration (SeaWiFS data), surface temperature, salinity and density (CTD "Lance" data) are shown in Figs. $(\mathbf{6 a}, \mathbf{b}, \mathbf{c})$, accordingly. These figures clearly show that closed contours of surface salinity and density coincide with areas of high chlorophyll-a concentration. This connection is especially visible in the area with the highest chlorophyll-a concentra- tion at $76^{\circ} \mathrm{N}, 30^{\circ} \mathrm{E}$, where we see a density anomaly of over 27.9 , indicating a surface patch of deep water.

The characteristic size of mesoscale eddies is determined by the internal Rossby deformation radius $R_{b}$. This was calculated for the conditions observed under the $\mathrm{R} / \mathrm{V}$ "Lance" survey. Values ranged from 4 to $6.5 \mathrm{~km}$ from southern side of PFZ (AtW), in a zone of maximum gradients to the north of PFZ (ArW).

Hydrodynamic instability of the non-uniform currents in the south and north PFZ [25], is the most probable reason for the formation of mesoscale eddies. In this case the wave 

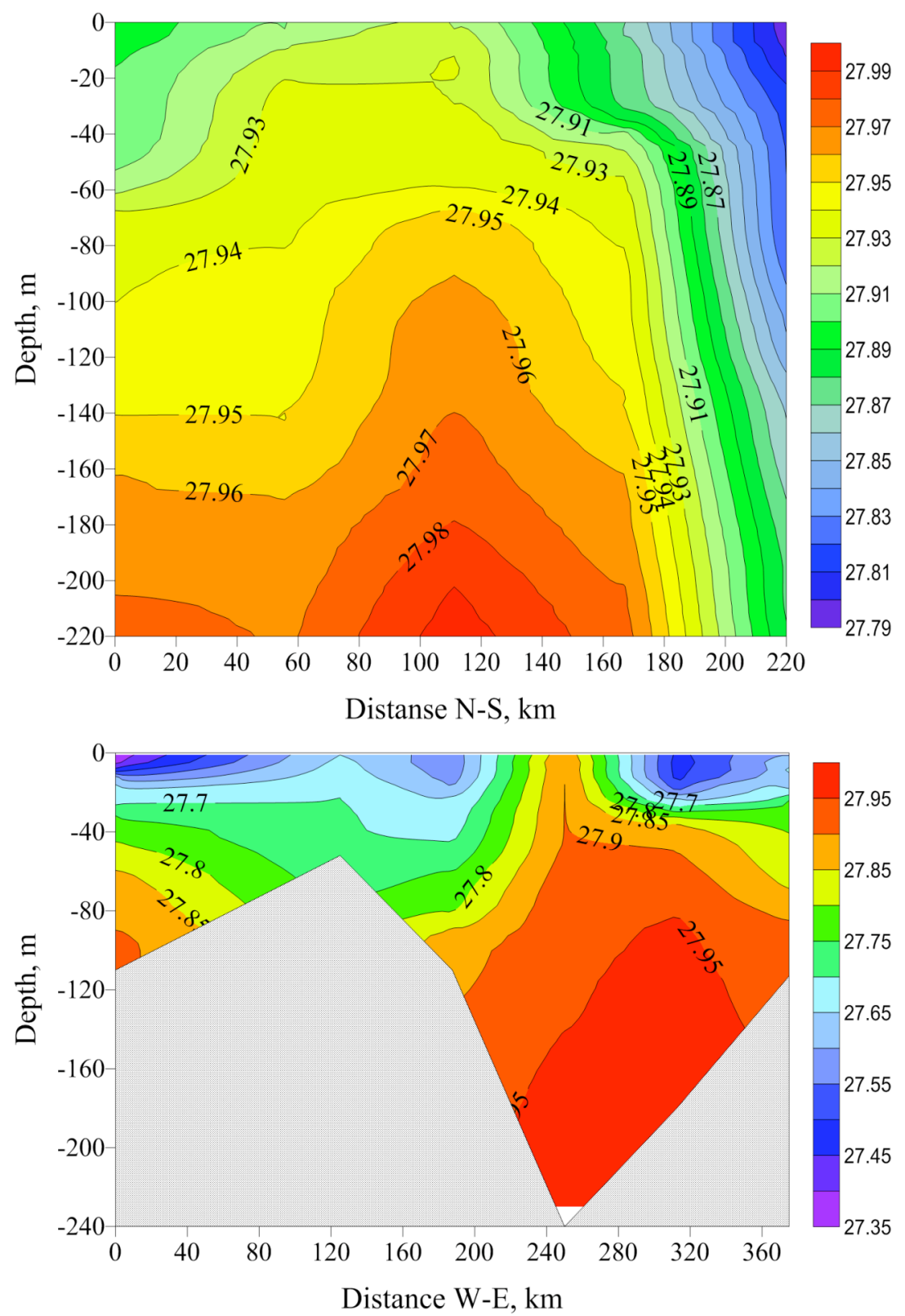

Fig. (7). Vertical sections of potential density $\left(\sigma_{\mathrm{t}}\right)$ along $30^{\circ} \mathrm{E}$, starting at $77^{\circ} \mathrm{N}, 30^{\circ} \mathrm{E}$ (top), and along $77^{\circ} \mathrm{N}$, starting at $77^{\circ} \mathrm{N}, 20^{\circ} \mathrm{E}($ bottom).

number, $\mathrm{k}=2 \pi / \mathrm{L}$, of the most unstable distortions is connected with internal Rossby deformation radius $R_{b}$ as follows: $\mathrm{k} \leq \mathrm{R}_{\mathrm{b}}{ }^{-1}$. Here $\mathrm{L}$ is the characteristic size of the mesoscale eddies. In this case $\mathrm{L} \geq(25-40) \mathrm{km}$, which agrees with the observed spatial scales of the chlorophyll-a flashes. These estimations agree with previous calculations carried out for the PFZ area in the Barents Sea [10].

Fig. (7) shows the vertical structure of the mesoscale eddy centred at $76^{\circ} \mathrm{N}, 30^{\circ} \mathrm{E}$, which is also a strong feature in the chlorophyll-a distribution. Two vertical sections in the potential density field are shown, one latitudinal and one longitudinal. One more section in the potential density field is presented in Fig. (8). This section is carried out along a longitude of $75.5^{\circ} \mathrm{N}$ from the point $75.5^{\circ} \mathrm{N}, 15^{\circ} \mathrm{E}$ and crosses the zone of the greatest horizontal gradients of the SST, at a site where a detailed survey was performed.
The dome-shaped structure caused by a local raising of deep water is visible in all the sections. This structure is characteristic for cyclonic mesoscale eddies. The transport of deep water with high nutrient concentration to the surface layer where photosynthesis takes place (euphotic zone) during late spring or early summer results in intensive phytoplankton production. This effect is seen clearly in the chlorophyll-a concentrations measured by remote sensing and in distributions of the CTD - parameters on R/V "Lance" data, in spite of the fact that this survey and the satellite image differ on time by approximately 10 days. This means that the mesoscale eddies with these scales have a lifetime of about 20-30 days, in agreement with detailed investigations of such structures in the marginal ice zone in the Fram Strait near Svalbard [23].

It should be noted that mesoscale eddies have a significant influence on primary production and biological 


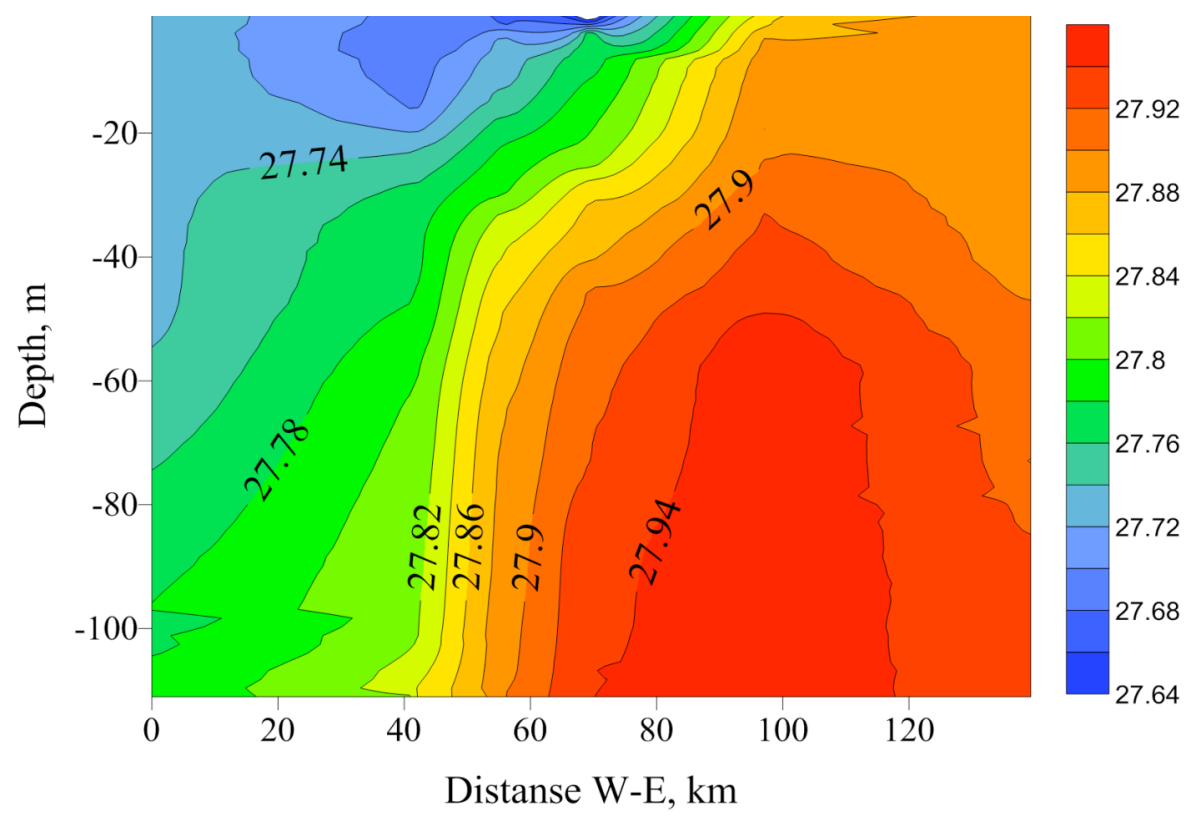

Fig. (8). Vertical structure of potential density $\left(\sigma_{\mathrm{T}}\right)$ on the section along $75.5^{\circ} \mathrm{N}$.

processes in many other areas of the World Ocean [21, 2628].

With respect to the delivery of deep water to the euphotic zone, the key quantity is the vertical velocity, $\mathrm{W}_{\mathrm{m}}$. Several methods of indirectly estimating the vertical velocity in mesoscale eddies are discussed in [29-32]. Because of the lack of the detailed information about the mesoscale eddies we are interested in, we are limited to an estimation of the scale of $\mathrm{W}_{\mathrm{m}}$.

$\mathrm{W}_{\mathrm{m}}$ is calculated from the ratio:

$\mathrm{W}_{\mathrm{m}}=\left(\frac{\mathrm{L}}{\mathrm{L}_{\mathrm{b}}}\right)^{2} \varepsilon_{\mathrm{T}} \frac{\mathrm{H}}{\mathrm{L}} \mathrm{U}$

where $\varepsilon_{\mathrm{T}}=1 / \mathrm{Tf}, \mathrm{H}$ is the sea depth, and $\mathrm{T}$ is the time scale of eddies, taken to be 20-30 days. $U$ is the scale of the horizontal velocity, which data from moorings in the Barents Sea suggest to be $10-20 \mathrm{~cm} / \mathrm{s}$ [25].

Assuming that $\mathbf{L}=(25-40) \mathrm{km}, \mathbf{L}_{\mathbf{b}}=(4-6.5) \mathrm{km}, \mathbf{H}=$ $200 \mathrm{~m}$, and $\mathbf{f}=1.4 \times 10^{-4} \mathrm{rad} / \mathrm{s}$, we obtain approximations for the minimum and maximum vertical velocity in the centre of the mesoscale eddies. These estimations range from 4 to 20 $\mathrm{m} /$ day. This range coincides with estimations of the vertical velocity that are typical for thermohaline convection that develops at the front between ArW and AtW [33].

\section{CONCLUSIONS}

1. The spatial structure of the PFZ in the spring and summer period is characterized by local areas of high chlorophyll-a concentration with short lifetimes ("flashes"). These chlorophyll-a flashes are formed sporadically in all the areas where AtW and ArW interact, from the coastal zone of Svalbard to Novaya Zemlya. Statistical characteristics of these flashes were determined from satellite measurements for the last 11 years. The timing of flash formation has a normal probability distribution, and the most probable period for their formation is the last week of May. The maximum values of the chlorophyll-a concentration have a Rayleigh probability distribution with an average of $3.82 \mathrm{mg} / \mathrm{m}^{3}$ and a standard deviation of $1.98 \mathrm{mg} / \mathrm{m}^{3}$.

2. The most probable mechanism of formation of the local areas of high chlorophyll-a concentration are mesoscale cyclonic eddies, where there is an effective transport of deep waters with high nutrient concentration up to the surface euphotic zone. The following factors testify for this: (i) the spatial size of the flashes corresponds the characteristic size of the eddies, (ii) the position of the eddies during the $\mathrm{R} / \mathrm{V}$ "Lance" survey coincides with zones of the high chlorophyll-a concentration derived from the optical SeaWiFS scanner.

3. Our results can form the basis for further investigations of the PFZ, in particular in the interests of commercial fishing. The results suggest that the following problems are worthy of further research: (i) What are the basic mechanisms of formation of the mesoscale eddies? Likely mechanisms are barotropic and baroclinic instability, topographic trapping, differential Ekman pumping along the ice edge, and ice edge instability driven by internal ice dynamics. These mechanisms probably interact with each other, for example, in the barotropic-baroclinic instabilities which can develop in the region where the velocity of AtW increases on the southern border of the PFZ. (ii) What factors determine the time scale of the flash? (iii) How do flashes influence the productivity in the region of the PFZ, and thus their significance for commercial fishing in these areas? We believe that further research will bring us closer to answering these questions. 


\section{ACKNOWLEDGEMENTS}

This work is carried out as part of the project "Norwegian component of the Ecosystem Studies of Subarctic and Arctic Regions (NESSAR)". The Research Council of Norway $(\mathrm{RCN})$, the International Polar Year initiative, funds the project.

\section{REFERENSES}

[1] Adlandsvik B, Loeng H. A study of the climatic system in the Barents Sea. Pol Res 1991; 10 (1): 45-9.

[2] Byshev VI, Galerkin LI, Galerkina NL. Thermochaline structure of the Barents Sea waters and its variability on the bases of observations in 1997-1998. Oceanology 2002; 42: 530-46.

[3] Curtin TB. Halocline water formation in the Barents Sea. J Geophys Res 1995; 100(C1): 881-94.

[4] Falk-Petersen S, Hop H, Budgel WP, et al. Physical and ecological processes in the marginal ice zone of the northern Barents Sea during the summer melt period. J Marine Syst 2000; 27(1-3): 13159

[5] Harris CL, Plueddemann AJ, Gavarkievicz GG. Water mass distribution and polar front structure in the western Barents Sea. J Gephys Res 1998; 103(C2): 2905-17.

[6] Loeng H. Features of the physical oceanographic conditions of the Barents Sea. Pol Res 1991; 10(1): 5-18.

[7] Loeng H, Sætre R. Features of the Barents Sea circulation. Fisken og havet 2001; 1: pp. 40.

[8] Loyning TB. Hydrography in the north-western Barents Sea, JulyAugust 1996. Pol Res 2001; 20(1): 1-11.

[9] Parsons AR, Bourke RH, Muench RD, et al. The Barents Sea Polar Front in summer. J Geophys Res 1996; 101(C6): 14201-21.

[10] Rodionov VB, Kostianoy AG. Oceanic Fronts of the NorthEuropean Basin Seas, GEOS, Moscow. 1998; pp. 293. (In Russian).

[11] Kushnir VM, Hansen E, Pavlov VK, Morozov AN. Thermochaline convection in the edge ice zone in the Barents Sea to the east of Spitsbergen. Mar Hydr J 2003; 6: 65-77. (In Russian). English translation in: Phys Oceanogr Nov 2003; 13(6): 361-74. doi:10.1023/B:POCE.0000013233.69589.d1.

[12] Engelsen O, Hegseth EN, Hop H, Hansen E, Falk-Petersen S. Spatial variability of chlorophyll-a in the Marginal Ice Zone of the Barents Sea, with relation to sea ice and oceanographic conditions. J Mar Syst 2002; 35(1): 79-97.

[13] Engelsen O, Hop H, Hegseth EN, Hansen E, Falk-Petersen S. Deriving phytoplankton biomass in the Marginal Ice Zone from satellite observable parameters. Intern J Remote Sensing 2004; 25(7-8): 1453-7.

[14] Johannessen OM, Shalina EV, Miles MW. Satellite evidence for an Arctic sea ice cover in transformation. Science 1999; 286: 1937-9.

[15] Reigstat M, Wassmann P, Riser CW, Oygarden S, Rey F. Variations in hydrography, nutrients and chlorophyll-a in the marginal ice-zone and the central Barents Sea. J Mar Syst 2002; 38(1-2): 9-29.

[16] Mitchell BG, Brody EA, Eueng-Nan Yeh, McClain C, Comiso J, Maynard NG. Meridional zonation of the Barents Sea ecosystem inferred from satellite remote sensing and in situ bio-optical observations. Pol Res 1991; 10(1): 147-62.
[17] Kogeler J, Rey F. Ocean colour and the spatial and seasonal distribution of phytoplankton in the Barents Sea. Intern J Remote Sensing 1999; 20 (7): 1303-18.

[18] Wassmann P, Ratkova T, Andreassen I, Vernet M, Pedersen G, Rey F. Spring bloom development in the marginal ice zone and the central Barents Sea. Mar Ecol 1999; 20(3-4): 321-46.

[19] Gregg WW, Casey NW. Global and regional evaluation of the SeaWiFS chlorophyll data set. Remote Sensing Environment 2004; 93(4): 463-79.

[20] Burenkov VI, Vedernikov VI, Ershova SV, Kopelevich OV, Sherberstov SV. Application of the ocean color data gathered by the SeaWiFS satellite scanner for estimating the bio-optical characteristics of waters in the Barents Sea. Oceanology 2001; 44(4): 461-8.

[21] Qu B, Gabric AJ, Matrai PA. The satellite-derived distribution of chlorophyll-a and its relation to ice cover, radiation and sea surface temperature in the Barents Sea. Pol Biol 2006; 29(3): 196-210.

[22] Morozov AN, Kushnir VM, Stanichny SV, Fedorov SV, Hansen E, Pavlov VK. Comparison of the data of satellite and direct measurements of the sea surface temperature in the Barents Sea. Proc Intentional Scientific and Technical Seminar "Monitoring Systems of the Environment-2005", Sept. 19-23, 2005, Sevastopol. Marine Hydrophysical Institute, National Academy of Science of Ukraine, Sevastopol, Ukraine 2005; 163-6.

[23] Johannessen JA, Johannessen OH, Svendsen E, et al. Mesoscale Eddies in the Fram Strait Marginal Ice Zone During the 1983 and 1984 Marginal Ice Zone Experiments. J Geophys Res 1987; 92(C7): 6754-72.

[24] Kostyanoy AG, Lebedev IA, Novikov BA, Rodionov VB. About eddies formation in the Polar frontal zone of the Barents Sea. Trudi AANII. Arctic and Antarctic Research Institute, St. Petersburg, Russia. (In Russian) 1992; 426: 19-32.

[25] Gancel J. Analysis of Current Meter Data in the Barents Sea. Tech Rep Norwegian Polar Institute 2001; pp. 50.

[26] Robinson AR, Ed. Eddies in Marine Science. Heidelberg: Springer 1983.

[27] Kushnir VM, Piontkovski SA. Synoptic Variability of the Vertical Current Velocity and its Coupling with Chemical and Biological Characteristics in the Northwestern Arabian Sea. In: Banse K, Piontkovsky SA, Eds. The Mesoscale Structure of the Epipelagic Ecosystem of the Open Northern Arabian Sea. Hyderabad, India: Universities Press 2006; pp. 193-237.

[28] Fossheim M, Zhou M, Tande KS, Pedersen OP, Zhu YW, Edvardsen A. Interactions between biological and environmental structures along the coast of northern Norway. Mar Ecol Progr Ser 300 2005: 147-58.

[29] Kamenkovich VM, Koshlyakov MN, Monin AS. Synoptic Eddies in the Ocean, Hydrometeoizdat, Leningrad, USSR 1982; pp. 264. (In Russian).

[30] Bulgakov SN, Kushnir VM, Martinez A. Black Sea vertical circulation and extremes of the hydrochemical and hydrooptical parameters. Oceanologica Acta 1999; 22(4): 367-80.

[31] Kushnir VM, Yunev OA, Fenenko ZZ. Influence of the synoptic vertical currents on the chlorophyll-a distribution in the Black Sea. Oceanology 1999; 39(2): 202-211. (In Russian, abstract in English).

[32] Leach $\mathrm{H}$. The diagnosis of synoptic-scale vertical motion in the seasonal thermocline. Deep-Sea Res 1987; 34: 2005-17.

[33] Kushnir VM, Pavlov VK, Morozov AN, Pavlova O. Convective instability in the ice edge area of the Barents Sea. Open Oceano J 2008; 2 : 18-27. 